\section{arquivos analíticos de políticas educativas \\ Revista acadêmica, avaliada por pares, independente, de acesso aberto, e multilíngüe}

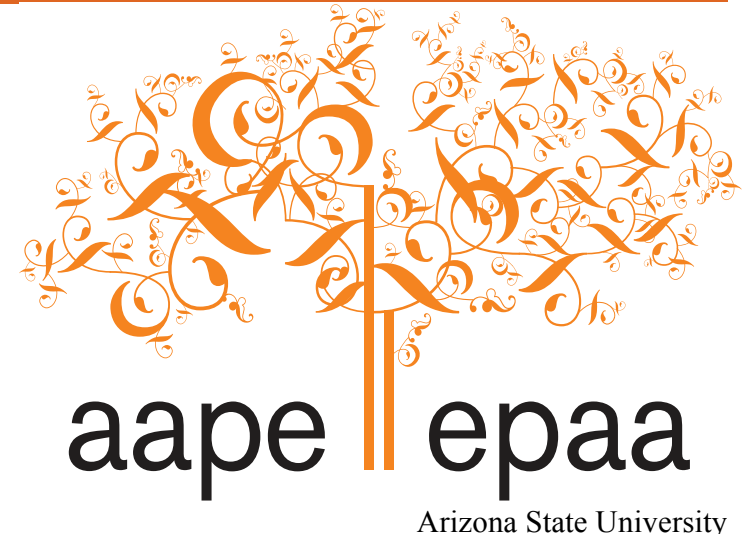

Arizona State University

\title{
As Ocupações Estudantis e a Reinvenção do Espaço Escolar Facilitadas pelas Tecnologias Interativas
}

\author{
Diego Felipe de Soura Queiror. \\ SEEDUC/RJ \\ Paula Chagas Bortolon \\ PPGICS/Icict/Fiocruz e Next/ENSP/Fiocruz \\ \& \\ Rita de Cássia Machado da Rocha \\ PGEBS/IOC/Fiocruz \\ Brasil
}

Citação: Queiroz, D. F. d S., Bortolon, P. C., \& Rocha, R. C. M. (2017). As ocupações estudantis e a reinvenção do espaço escolar facilitadas pelas tecnologias interativas. Arquivos Analíticos de Políticas Educativas, 25(104). http://epaa.asu.edu/ojs/article/view/mmm

Resumo: A grave crise do sistema educacional brasileiro, que vai do sucateamento dos colégios e das condições de trabalho à redução do que seria educar, há anos suscita movimentos de resistência e luta para a melhoria da educação. Em 2015, uma nova onda de manifestações surgiu, inicialmente em São Paulo, devido ao anúncio de fechamento de mais de 100 escolas públicas estaduais, o que fez o movimento estudantil emergir em âmbito nacional. No estado do Rio de Janeiro, mais de 80 escolas foram ocupadas pelos estudantes. Impulsionado pelas tecnologias interativas, para além da conquista do espaço físico escolar, este movimento é uma 
forma de oposição ao poder do Estado. Sua grande novidade é a subversão à lógica da escola tradicional, o que permitiu aos estudantes experimentarem a autogestão e vivenciarem uma nova dinâmica de ensino.

Palavras-chave: educação; ensino; tecnologias interativas; internet; movimento ocupa

\section{The students' Occupation and the reinvention of the schooling space enabled by the interactive technologies}

Abstract: For years now, the severe crisis of the Brazilian educational system, from the depreciation of schools and of working conditions to the overall decline in what education means, has been giving origin to movements of student resistance and struggle that demand improvement of education. In 2015, a new wave of protests started initially in São Paulo as a reaction to the government's announcement to close more than 100 state schools, which spread to similar manifestations nationwide. In the state of Rio de Janeiro over 80 schools were occupied by students. Boosted by interactive technologies, these students took the occupation of school spaces beyond, into a movement of opposition to the State power. The greatest innovation of the students' Occupation was the subversion of traditional school logic, enabling the students to experience self-management and a new dynamic form of education.

Keywords: education; teaching; interactive technologies; Internet; Occupy

\section{La Okupación de los estudiantes y la reinvencíon del espácio escolar habilitada por las tecnologías interactivas}

Resumen: Durante años, la severa crisis de la educación en Brasil, que va desde la depreciación de las escuelas y de las condiciones de trabajo hasta la reducción de lo que debiera ser educar, hay incitado movimientos de resistencia y lucha para mejoras en la educación. En 2015, una nueva ola de protestos comenzó inicialmente en São Paulo debido al anuncio del estado de cerrar más de 100 escuelas y se extendió por todo el país. En el estado de Río de Janeiro más de 80 escuelas fueron ocupadas por los estudiantes. Impulsados por las tecnologías interactivas, además de la consecución del espacio físico de la escuela, este movimiento es una forma de oposición al poder del Estado. La gran novedad es la subversión de la lógica de la escuela tradicional, que permitió a los jóvenes experimentar la autogestión y la experiencia de una nueva dinámica de enseñanza.

Palabras-clave: Educación; enseñanza; tecnologías interactivas; Internet; movimiento okupaemergencia

\section{Introdução}

A educação pública no Brasil há anos enfrenta uma crise que tem levado educadores a se mobilizarem e promoverem variados processos de luta. Já em 1953, Anísio Teixeira denunciava a crise da educação brasileira, afirmando que o desenvolvimento brasileiro trazia impactos para a educação, reduzindo seu papel na sociedade às vantagens que a formação escolar poderia oferecer e não mais aos ensinamentos em si. Passar nos exames tornou-se, então, o objetivo máximo dos alunos e também dos professores, o que diminui a importância dos estudos e os faz despropositais e contraditórios, podendo até ser algo nocivo à sociedade (Teixeira, 1953).

Assim como em outros estados do país, a crise da educação também atinge a rede estadual do Rio de Janeiro há muitos anos. A precarização dos serviços públicos no Rio de Janeiro tem sido 
uma constante durante diversos governos, com sucessivos cortes ${ }^{1}$ de investimentos nas áreas da saúde e da educação, que levaram a um intenso sucateamento das unidades escolares e de saúde. Além disso, as políticas adotadas têm tornado instáveis as condições salariais dos servidores públicos, devido aos sucessivos congelamentos das folhas de pagamento e de péssimas condições de trabalho. Para a educação, isto se reflete em salas de aulas superlotadas, com instalações precárias e muitas vezes em horários "quebrados", que obrigam os professores a darem aulas em diversos colégios para o cumprimento da suas cargas horárias de trabalho. Atualmente, a realidade tenebrosa dos serviços públicos no Rio de Janeiro foi evidenciada por meio da declaração de falência do governo estadual, que se deveu ao não fechamento das contas provocado por diversos motivos, dentre os quais: a gastança com políticas de isenção fiscal para empresas e o desvio de dinheiro público para esquemas de corrupção, que impôs aos servidores atrasos, parcelamentos e calotes de seus rendimentos.

Nos últimos cinco anos foram promovidas quatro greves na rede estadual fluminense, duas delas de maior destaque: a mobilização grevista de 2013, que serviu para revigorar e estender o grande acontecimento das jornadas de junho, que ocorreram neste mesmo ano, marcadas por mobilizações políticas ocorridas em todo Brasil a partir dos protestos contra o aumento de tarifas de transporte público; e a greve de 2014, que fortaleceu o movimento de crítica à realização do mega evento da Copa do Mundo no Brasil, pautado pelo questionamento aos gastos com este evento em detrimento de outros setores necessários e fundamentais para o desenvolvimento do país, como a educação e a saúde.

Nestes mesmos anos, no entanto, a mobilização discente não estava conseguindo ganhar a relevância que tivera durante anos anteriores, tal como durante a luta pela defesa do passe livre e contra as restrições da bilhetagem eletrônica no início dos anos 2000. Com o movimento de ocupações de escolas em São Paulo, já em 2015, realizado pelos estudantes contra o projeto de reorganização da rede de ensino que intentava o fechamento mais de 100 escolas, o movimento estudantil voltou a ganhar força em âmbito nacional.

Depois da mobilização ocorrida no estado de São Paulo, que a partir de novembro de 2015 levou à ocupação de mais de 200 escolas, estudantes de outros estados também se levantaram, em um movimento de sincronização Strogatz (2004) e emergência Johnson (2003). O conceito de sincronização remete-se aos fenômenos onde há interação entre dois ou mais sistemas, neste caso, a colaboração entre os estudantes em seus colégios, a ponto de surgir uma ordem coletiva, um "andar juntos", no qual a sincronia é percebida não pela análise de casos isolados, mas pelo conjunto das ações promovidas pelos participantes. Por outro lado, o conceito de emergência, desenvolvido por Johnson (2003), nos remete a diversos exemplos de situações onde organismos simples geram estruturas muito complexas, como, por exemplo: a inteligência coletiva de animais sociais; softwares

\footnotetext{
1 Os cortes em investimentos públicos que afetam diretamente as áreas da educação e também da saúde podem ser acompanhados pelos dados do Departamento Intersindical de Estatística e Estudos Socioeconômicos (DIEESE) e as denúncias são constantemente veiculadas nos jornais locais, como nos exemplos seguintes: 1) Materiais DIEESE: Material de estudo sobre campanha salarial dos educadores: http://www.seperj.org.br/admin/fotos/boletim/boletim181.pdf; Receitas e despesas gerais de recursos da educação do Estado do Rio de Janeiro: http://www.seperj.org.br/admin/fotos/boletim/boletim725.pdf; Evolução salarial dos educadores no Rio de Janeiro até 2013: http://www.seperj.org.br/admin/fotos/boletim/boletim182.pdf 2) Matérias veiculadas em jornais locais: https://oglobo.globo.com/rio/escolas-estaduais-terao-corte-de-102-milhoes-este-ano-18461249 http://g1.globo.com/rio-de-janeiro/noticia/2016/02/orcamento-do-rj-tem-r-18-bilhoes-menos-em2016.html; https://oglobo.globo.com/rio/pezao-determina-corte-de-184-bilhoes-no-orcamento-18613629 http://diariodorio.com/cabral-corta-verbas-de-educacao/
} 
que são capazes de gerar resultados complexos se valendo de algoritmos simples; o funcionamento das células cerebrais; e o comportamento aparentemente caótico de crescimento dos grandes aglomerados urbanos. Em síntese, emergência evidencia "o movimento de regras de nível mais baixo para a sofisticação de nível mais alto" (Johnson, 2003, p. 14). E é exatamente isto que se pode perceber nas ocupações estudantis: um movimento de sincronização e emergência, realizado diretamente pelas bases, partindo das singularidades dos estudantes espalhados por escolas de diversas cidades, que possibilitou o levante secundarista para uma política maior, cuja subversão ao poder constituído do Estado decorreu de um poderoso movimento de recriação do espaço escolar.

Em Goiás, 27 escolas foram ocupadas por estudantes contra medidas que incluíam: o fechamento de colégios integrais, transferência da administração de escolas públicas para o setor privado a partir de Organizações Sociais (OSs) e a militarização da educação por meio da transferência administrativa de colégios para a secretaria de segurança. No Rio de Janeiro, no dia 21 de março de 2016, motivados por uma nova greve de trabalhadores da rede de ensino estadual, estudantes da Ilha do Governador ocuparam o Colégio Prefeito Mendes de Moraes e, a partir daí, mais de 80 escolas deste estado também foram ocupadas. O processo de ocupações espalhou-se por mais de 23 cidades e por toda a zona metropolitana da cidade do Rio de Janeiro.

Os estudantes do Rio de Janeiro defenderam uma longa lista de reivindicações, que dentre os muitos pontos comuns estavam: a democracia nas escolas através de eleição direta para diretores; o fim da política de avaliações externas ${ }^{2}$; o enriquecimento da grade escolar por meio da ampliação da carga horária de disciplinas como Sociologia e Filosofia que, desde 2012, contam com apenas 40 minutos de aula semanais; a valorização dos trabalhadores da educação e reformas estruturais nos colégios, com pautas que englobam a valorização salarial, a luta contra a dupla função de trabalhadores e variadas demandas de melhorias e manutenção nas estruturas sucateadas das instalações físicas das escolas da rede de ensino estadual (Figura 1).

\footnotetext{
${ }^{2}$ Entendendo como avaliações externas os mecanismos de avaliações nacionais e internacionais colocados de forma verticalizada pelos governos para ranquear as instituições escolares dentro de uma lógica meritocrática de desempenho e materializada na rede de educação estadual pelas provas do SAERJ (Sistema de avaliação da educação do Estado do Rio de Janeiro).
} 


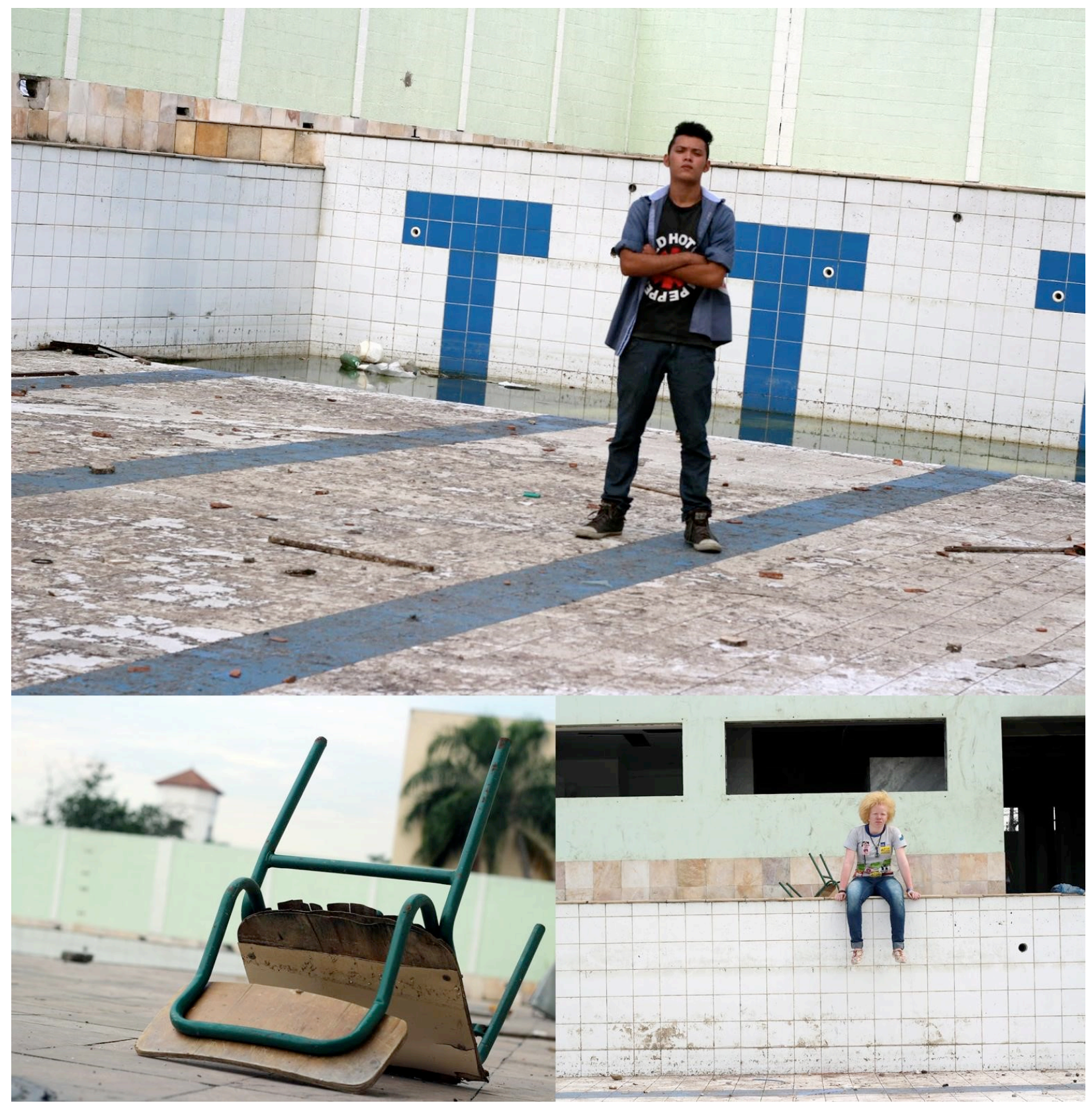

Figura 1. Estudantes mostram o descaso com a estrutura física do espaço escolar no Colégio Estadual Compositor Luiz Carlos da Vila (RJ) em maio de 2016. Fonte: Coletivo de mídia independente Linhas de Fuga.

Vale a pena esclarecer que o processo avaliativo do sistema educacional do Rio de Janeiro é baseado em uma política de metas e bonificação, cuja proposta baseia-se na lógica produtivista, não trazendo medidas efetivas de melhoria da qualidade da educação pública. Neste modelo, o professor é forçado a produzir números positivos para o Índice de Desenvolvimento da Educação Básica (IDEB), sem que isto altere, de fato, a realidade concreta das escolas em que estão inseridos. A questão central desta política é baratear os custos da educação, de acordo com a ideologia neoliberal de diminuição do Estado e submissão da formação escolar para as demandas do mercado de 
trabalho, sem levar em consideração os anseios e vontades dos atores envolvidos no processo educativo. Dentre as ações desenvolvidas neste modelo aparecem planos de bonificação, que substituem a valorização material dos servidores (colocadas por reajustes, aumentos salariais e por plano de carreiras associados ao tempo de serviço); gratificações, que variam de acordo com a produtividade dos profissionais; a contratação de empresas gestoras para diversos serviços dentro das instituições escolares; e também políticas de avaliação de premiação de desempenho das unidades escolares. As consequências da política avaliativa apontam para a desvalorização dos profissionais de educação e para a criação de relações de concorrências, tanto entre profissionais quanto entre as escolas, resultando em padrões de formação escolar desiguais, além de subordinar a gestão escolar a pessoas e empresas que não tem propriedade sobre os objetivos e a função pública da educação (Frigotto, Motta, Gama, \& Algebaile, 2011).

Os efeitos disso recaem diretamente sobre os estudantes, que acabam submetidos a um sistema de educação que mascara os problemas concretos da escola: em uma realidade onde seus professores são desvalorizados financeiramente e obrigados a trabalhar em péssimas condições, é inevitável a diminuição da qualidade das aulas que lhes são lecionadas. Além disso, a política empregada para avaliação das escolas também tende a ignorar as singularidades de cada ambiente escolar, o que é um grande problema quando se trata de um sistema de educação que engloba uma realidade de imensas desigualdades.

Estas constatações despertaram algo inovador nas ações realizadas pelos estudantes neste cenário de ocupações dos colégios: diferentemente do que se esperaria da cultura política tradicional, representada pelas típicas ações das entidades do movimento estudantil, com suas ações partidárias e burocrática, que tentam dirigir-se ao Estado em busca de conquista de espaço no plano macropolítico, cujas redes sociais formadas são burocráticas, rígidas e centralizadas, os estudantes vivenciaram a força das práticas políticas moleculares (Guattari, 1980; Guattari \& Rolnik, 2005). Este conceito busca definir a sociedade no que tange à sua organização micropolítica (molecular), que, ao contrário da conformação macro (molar), considera as subjetividades e organiza-se em redes flexíveis, complexas e produtoras de conflitos e linhas de fuga, estas entendidas como as ações que se desejam realizar, seja no plano da análise ou no da intervenção. Esta possibilidade dos estudantes serem sujeitos ativos no processo de luta por uma educação pública de qualidade, tornando-os protagonistas de seus próprios feitos, produzindo suas linhas de fuga, foi potencializada pelo uso da internet.

A internet, tecnologia que configura o sistema global de redes (que se iniciou com o uso de computadores, mas hoje se estende a outros dispositivos), permite experimentar uma conexão como jamais antes na história da humanidade. Ao passo que esta tecnologia evolui e se difunde pelo mundo há um rompimento com características culturais e paradigmas das tecnologias anteriores, marcadas por sistemas simples e fechados, cujas estruturas de rede eram hierárquicas, centralizadas, não interativas e voltadas aos processos comunicativos intersubjetivos. A internet dos dias atuais modifica toda esta lógica. Constituída por redes distribuídas, típicas de sistemas complexos, o caráter extremamente interativo que a internet dos anos 2000 assumiu amplia a possibilidade de participação dos indivíduos e permite construir práticas colaborativas que geram dinâmicas emergentes, isto é, de baixo para cima. Por isso, a internet não seria apenas uma "nova" tecnologia de comunicação e informação, que precipitadamente poderia ser entendida como mais uma no conjunto das tecnologias de sistemas simples. Seria, então, uma "tecnologia interativa" (Santos, Santos, Melca, Bortolon, \& Rocha, 2014a), a mais dinâmica e potente que temos hoje e, por isso, ao se referir ao termo "tecnologias interativas" neste estudo de caso, subentende-se que se trata diretamente da internet, representada por seus aplicativos e redes sociais. 
Foi por meio da internet que as notícias sobre as ocupações estudantis rapidamente se espalharam por todos os cantos do Estado do Rio de Janeiro e incentivaram outros estudantes a também aderirem à ocupação das escolas, movimento este que foi se consolidando tanto em função do compartilhamento de experiências, estratégias e ações realizadas no dia a dia das ocupações, contando com um processo de "aceitação", construído dentro das redes sociais da internet, que trouxe aos estudantes o apoio da sociedade.

Dessa forma, as ocupações não são marcadas apenas por conquistas de "territórios" para demonstrar certo poder político frente ao governo do Estado, mas se constituem como espaços de empoderamento social, político e cognitivo, no qual se questiona o status quo do modelo educacional vigente e se experimenta uma nova vivência de ensino, mais horizontal e menos hierárquica, e que busca no poder da criatividade e da inovação um caráter transformador.

Entender de que forma as críticas à escola tradicional e as práticas promovidas pelo movimento das ocupações estudantis podem contribuir para que se pense um outro modelo de Escola e educação é um caminho que pode nos mostrar um futuro mais alinhado à nossa época, na qual a informação, a comunicação e a educação sofrem influências diretas do mundo conectado.

\section{Da Escola Tradicional à Recriação do Espaço Escolar}

A crítica ao que foi denominado "Escola Tradicional" não é nova e remonta a experiências promovidas desde o século XIX. Para Aranha (2006), a "Escola Tradicional" é entendida como um movimento que inclui:

Diversas tendências no decorrer de pelo menos quatro ou cinco séculos (desde o século XVI até o século XX), período em que a escola tradicional sofreu inúmeras críticas e transformações (...), sobretudo pelas pedagogias inovadoras do século XX (Aranha, 2006, p. 224).

Como é destacado por Aranha (2006), analisar de forma homogênea o que seria "Escola Tradicional" dentro deste longo período é um trabalho demasiadamente longo, que facilmente pode acarretar uma postura reducionista, uma vez que este espaço também abriga resistência e inovação. No entanto, é comum a caracterização da educação tradicional para fins de entendimento didático. Quando falamos em "Escola Tradicional", nos referimos a uma pedagogia magistrocêntrica, que entende o educador como provedor de conhecimento e os estudantes como meros receptores, e também uma concepção de formação que valoriza aulas expositivas, exercícios de memória destinados a assimilação de conteúdo, currículos, horários rígidos e o desenvolvimento da disciplina por meio da vigilância e da obediência.

Neste contexto, a educação é entendida como um processo pelo qual se introduz um conhecimento no educando. As relações sociais hierarquizadas primeiramente se apoiavam em mecanismos coercitivos e repressivos, com castigos e premiações. Depois, a hegemonia ideológica, firmada sob a égide da autoridade pela experiência e pelo saber especializado, perpetuou este caráter hierárquico assimétrico das relações educacionais. Além disso, vale ressaltar que este sistema educacional se consolidou em um cenário de número restrito de informações, o que propiciou ser esta a unidade de saber, a expressão e a "representação" da "verdade". O valor, assim, esteve centrado no conteúdo (N. B. dos Santos, 2005). É esse modelo de educação que Paulo Freire denominou como Educação Bancária, que coloca os educandos como meros receptores das informações, as quais devem guardar e arquivar categoricamente para uso posterior (Freire, 2005). 
Concepções pedagógicas anarquistas, tais como a de (Ferrer Guardia, 1905), e experiências de escolas libertárias, como a Colmeia (La Roche) de Faure (2015), foram pioneiras na crítica à escola de caráter burguês liberal edificada pelos Estados Modernos. O movimento da Escola Nova também propôs outros caminhos para a educação, buscando desenvolver um modelo de formação não essencialista que pudesse adaptar-se ao dinamismo do mundo industrial marcado por constantes transformações políticas e econômicas. A proposta de educação da Escola Nova deslocou o centro do processo de aprendizagem para o estudante, entendendo o professor como um facilitador de aprendizagem. Apontou ainda que a construção do conhecimento é mais importante do que o conteúdo dado; que as avaliações e processos pedagógicos não poderiam estar afastados das experiências dos discentes; e também chamou atenção para a ideia de disciplina voluntária e do desenvolvimento da democracia escolar. No Brasil, o movimento da Escola Nova, iniciado na década de 1920, explicitou suas ideias no Manifesto dos Pioneiros da Educação Nova (1932), ajudando a divulgar as ideias de John Dewey, cuja teoria assumia a importância da abordagem "aprender fazendo".

Anísio Teixeira, educador brasileiro, ficou conhecido como grande crítico do elitismo escolar vigente no país, afirmando que a educação deveria ser entendida como um direito de todos. Uma das experiências deste pedagogo foi a criação, em Salvador, do Centro Educacional Carneiro Ribeiro, mais conhecido como Escola Parque, que se tornou um centro pioneiro de ensino integral (Teixeira, 1953, 1967a, 1967b). No entanto, a ideia de "escola redentora", aquela que por si mesma poderia resolver os problemas e contradições da realidade social e de aprofundamento democrático por meio da meritocracia liberal, se reverteu em um otimismo pedagógico demasiadamente irreal. $\mathrm{O}$ projeto escolanovista encontrou muitas outras dificuldades, tais como a deturpação de seus preceitos e dificuldades práticas para a implementação de suas teorias.

A partir de 1968, na França, e da abertura política no Brasil, desenvolveram-se novas concepções sobre a educação, que criticavam a ideia de "escola redentora", entendida como espaço de reprodução ideológica da classe dominante. As teorias de Bourdieu \& Passeron (1975) sobre a Violência Simbólica; de Althusser (1998) sobre Aparelho Ideológico do Estado; e de Baudelot e Establet sobre o Dualismo Escolar apud Aranha (2006), apontaram para o desenvolvimento de uma visão crítico-reprodutivista da escola, cujos fundamentos centrais repousam em críticas às teorias liberais, e defendem que a instituição escolar funciona para reproduzir as diferenças sociais e perpetuar o status quo. Toda esta tendência fundamentou fortemente o porquê do fracasso da escola para a classe trabalhadora, contudo não apontou explicitamente propostas pedagógicas alternativas.

Entre os anos 70 e 80 do século XX, a mobilização dos educadores no Brasil em busca de uma educação crítica voltada para a superação das desigualdades fez surgir a "pedagogia libertadora" (Dussel, 1995; Freire, 1980, 2005). Esta é uma tendência pedagógica que visa à construção de um processo formativo focado na discussão de temas sociais e políticos e em ações concretas sobre a realidade social. Para esta concepção, a escola deveria funcionar de forma conscientizadora, problematizando a realidade social e trabalhando para a sua transformação. Paulo Freire foi o mais conhecido defensor desta tendência pedagógica, ficando conhecido por suas obras teóricas de forte cunho político e suas propostas pedagógicas voltadas para autonomia dos estudantes. Seus métodos e teorias são utilizados até hoje na educação "acelerada" de jovens e adultos; contudo, muitas das suas ideias também foram aplicadas de forma deturpada por políticas públicas por todo país, tal como a implantação dos ciclos educacionais na educação municipal da cidade do rio de Janeiro ${ }^{3}$.

\footnotetext{
3 Política implantada pelo governo de Cesar Maia em 2007 para substituir o regime de séries. Uma política retoricamente fundamentada na ideia de progressão continuada, para em essência diminuir o atraso e evasão escolar, mas que, sem nenhum tipo de acompanhamento que viesse a suprir as necessidades pedagógicas dos
} 
Utilizada como uma alternativa à educação por séries, prevista na Lei de Diretrizes e Bases da Educação (Brasil, 1996), a educação por ciclos, cuja proposta pedagógica consiste na progressão continuada por ciclos que duram de três a cinco anos, com avaliações ao final de cada ciclo, foi implantada pela Prefeitura do Rio de Janeiro em 2007, mas, na prática, traduziu-se como um projeto de aprovação automática que mascara o problema da repetência no Brasil.

A realidade prática sempre impôs diversos obstáculos para que de fato se rompesse com os fundamentos da "educação bancária", afinal, a instituição escolar nos dias de hoje é orientada por políticas públicas de governos voltadas para massificar a educação de forma a propiciar mão de obra acrítica e barata para o mercado. Por mais que existam professores e projetos destinados a promover um outro modelo de educação, estes acabam tendo suas ações limitadas e sucumbem diante do modelo de educação formal constituído.

O movimento de ocupação das escolas possibilitou levantar reflexões e experimentações que transcendem o campo da institucionalidade e a lógica governamental. Nas ocupações, a disciplina e hierarquia burocrática foram subvertidas de forma radical, permitindo aos estudantes transformarem as escolas em espaços marcados pela autogestão - processo que conta com estruturas altamente organizadas, dominadas e, principalmente, gerenciadas pelos participantes, baseadas na participação livre e voluntária, e que resulta na criação de comunidades cooperativas, as quais realizam assembléias gerais, serviços de alimentação, limpeza, apoio, segurança e assim por diante (Chomsky, 2012).

No desenvolver de todo este processo, construído na prática do dia a dia e de acordo com as necessidades dos estudantes, amadureceram-se os questionamentos sobre o projeto neoliberal de merco-escola, que coloca a educação como mercadoria a serviço das empresas e indústrias, preparando os estudantes para a competitividade do mercado de trabalho e trabalhando o currículo escolar a fim de que se tornem passivos diante dos padrões impostos pelos modelos ideológicos neoliberais(Gentili, 1998, 2002; Santos \& Mesquita, 2007). Este modelo educacional favorece o desemprego e a marginalidade, uma vez que reproduz padrões de exclusão em nossa sociedade (Gentili, 2001). Desse modo, a luta estudantil, à medida que defendia o fim das avaliações externas e da política de currículo mínimo, que versam sobre resultados educacionais e planos de ensino tecnicamente pré-determinados, também se contrapôs à concepção taylorista, a qual:

(...) propõe a divisão de tarefas entre diversos técnicos de ensino incumbidos do planejamento racional do trabalho educacional, cabendo ao professor a execução em sala de aula daquilo que foi projetado fora dela. Para tanto, nas reuniões de planejamento os objetivos institucionais e operacionais são rigorosamente esmiuçados, estabelecendo-se um ordenamento sequencial de metas a serem cumpridas (...). Nessa perspectiva, o professor é um técnico que, assessorado por outros técnicos, transmite um conhecimento técnico e objetivo (Aranha, 2006, p. 231).

O projeto governamental alienante de educação positivista e mercadológica, baseado na mensuração quantitativa dos conteúdos aprendidos e no treinamento comportamental dos alunos por meio do desenvolvimento de habilidades requeridas objetivamente para o mercado de trabalho, é contraposto pela pauta de ampliação da carga horária de disciplinas humanísticas, tais como Filosofia e Sociologia, além de haver demanda por oficinas e outros processos de formação que extrapolam o tradicional sistema de currículos, disciplinas, séries e horários rígidos e inflexíveis.

alunos, se consolidou em uma "política de aprovação automática de estudantes", já que inviabilizou a retenção dos estudantes dentro das fases de progressão. 
Todas estas pautas críticas, desta vez, não se limitaram a uma postura reativa contra o modelo de escola tradicional e os projetos governamentais vigentes. Por meio de realizações práticas de intenso poder constituinte, os estudantes promoveram a construção de um outro paradigma de formação, que apontou para a possibilidade de outro modelo de escola e de educação, independentemente das normas e práticas oficiais vigentes.

\section{As Tecnologias Interativas como Facilitadoras do Levante Estudantil Carioca}

A construção de uma educação emancipatória sempre necessitou de condições políticas e sociais para se fazer valer diante das práticas e políticas hegemônicas colocadas pelos poderes públicos e privados. Já há algum tempo a:

Educação foi obrigada a se renovar pensando métodos pedagógicos e tecnológicos que não priorizam a transmissão de informações e que incorporam interatividade no processo educativo como é o caso, por exemplo, das teorias construtivistas. Mas, devido às restrições criadas pelas tecnologias utilizadas, a prática educativa era obrigada a manter suas características fundamentais (teoria separada da prática, isolamento espacial, atividades basicamente síncronas, hegemonia e controle quase absoluto do processo educativo por parte do professor, etc) (Santos, 2006, p. 59).

Atualmente, a prática educativa tem sido modificada pela utilização de tecnologias para a realização de processos educacionais formais e não formais. Isto porque, com a consolidação da internet, surge um sistema capaz de universalizar registros e acesso às informações, estabelecer a comunicação em tempo real, livre das variáveis de espaço e tempo, aumentar consideravelmente a interatividade e permitir o processamento de um número infinito de informações, o que criou uma série de problemas novos para a dinâmica educativa tradicional, mas que possibilitou pensar novos tipos de práticas cognitivas (Santos, 2005).

Não faz mais sentido exigir no ensino a memorização de conteúdo se a rede funciona já como uma imensa prótese de memória, com terabytes de informação armazenados e disponíveis para consulta. Por outro lado, atividades relacionadas à resolução de problemas, pensamento crítico, autonomia e cooperação são incentivadas (Santos, Martins, \& Santos, 2014b, p. 3).

As mídias digitais a que hoje temos acesso provocam novas dinâmicas em relação ao processo de aprendizagem tradicional (...). Surge um modelo pedagógico próprio, que não substitui os modelos anteriores, mas o complementa, onde são desenvolvidas novas expectativas de liberdade de acesso, de conexão contínua e de colaboração (Santos, Martins, \& Santos, 2014b, p. 5).

A emergência estudantil e as experiências educacionais das ocupações não podiam deixar de estar relacionadas à internet, na medida em que, diferentemente de outras tecnologias, ela rompe com o funcionamento padrão dos meios de comunicação de massa e permite uma comunicação sem mediações e centralização, marcada pela configuração dos sistemas distribuídos, em que todo elemento pode ter acesso a qualquer outro elemento da rede, permitindo que o processo comunicativo ocorra de "todos para todos".

A característica de rede distribuída que a internet tem também faz com que ela seja um espaço de não-controle, onde as transformações sociais têm lugar. Ao explicar sobre a "sociedade pedagógica", Serres (2000) diz que se trata desta nova sociedade que se forma buscando informações em fontes diversas e que acaba aprendendo sobre determinados assuntos, muitas vezes mais do que técnicos, ou mostrando outro conhecimento, desconhecido dos técnicos, e contribuindo para a 
construção do conhecimento. Para ele, isto acontece porque as tecnologias atuais, precisamente a internet, permitem que qualquer pessoa tenha acesso a um número infinito de informações, sendo estas pertencentes a um espaço de não-controle, ou seja elas não são validadas, controladas. Em nossa sociedade, estamos acostumados com espaços de direito, espaços jurídicos, controlados. A internet é um espaço de não-direito, onde as transformações têm lugar. Ainda sobre isso e retomando as análises de Deleuze sobre Foucault no tocante à "sociedade de controle", Serres (2000) diz que a sociedade de controle se pauta inteiramente pelo direito, existindo regras que vigiam a sociedade. A internet rompe com este paradigma.

As recentes ocupações estudantis em São Paulo, Goiás e Rio de Janeiro são exemplos práticos e radicais disto. Assim como os processos políticos mundiais promovidos pela Multidão Hardt \& Negri (2005) - conceito desenvolvido para se referir à base política, social e econômica que compõe os novos movimentos sociais protagonistas do recente ciclo mundial de lutas - só puderam acontecer devido a uma mudança de paradigma concernente ao desenvolvimento tecnológico da comunicação, o levante secundarista no Brasil também está relacionado à apropriação da internet e das redes sociais pela juventude em luta. Para além do fato político, o uso da internet e das redes sociais também tiveram um papel fundamental na organização das práticas de autogestão além de serem centrais no processo de repensar as práticas pedagógicas adotadas no ensino no Brasil.

O aplicativo de comunicação instantânea WhatsApp Messenger, ou simplesmente Whats App, teve papel elementar nas movimentações políticas que levaram às ocupações. Criado em 2009 por uma empresa homônima e adquirido, em 2014, por Mark Elliot Zuckerberg, criador do Facebook, o Whats App tem gerado muitas polêmicas nos debates sobre comunicação, como a luta da empresa contra as corporações de telefonia, uma vez que este serviço de mensageria funciona por meio do número de telefone celular e pelo acesso à internet, seja ela wi-fi, 3G ou 4G. Ele também permite a comunicação em tempo real por meio de textos, áudios, fotos e vídeos, além de fazer ligações e possibilitar o envio e recebimento de documentos de variados formatos.

Devido a estas funcionalidades, o Whats $A p p$ foi apontado, pelos estudantes de várias ocupações no Estado do Rio de Janeiro, como imprescindível para organização coletiva durante o processo de "tomada" das unidades escolares, de acordo com os dados coletados no processo de entrevistas videográficas realizadas desde o início das ocupações pelo Coletivo Linhas de Fuga ${ }^{4}$, que passou por mais de 15 colégios espalhados por todo Estado para a produção, na época, de um documentário sobre este movimento ${ }^{5}$. O aplicativo foi considerado essencial, sobretudo para contrapor a estratégia coercitiva das direções escolares de proibirem reuniões e aglomerações de estudantes, objetivando impedir o avanço das ocupações.

Acontece que, no ambiente virtual dos grupos de Whats $A p p$, era possível realizar reuniões e ali mesmo discutir estratégias e ações a serem realizadas nas ocupações sem a necessidade de um encontro presencial e simultâneo entre os participantes, o que dificultava o controle por parte da direção dos colégios e do próprio Estado, além de facilitar a tomada de decisão dos estudantes pois, por ser um local de encontro, permitia também manter a união e o apoio entre eles. Apesar do endurecimento das medidas repressivas após as primeiras ocupações, o fenômeno do uso deste aplicativo não demorou a espalhar-se por dezenas de colégios, tendo a comunicação dinâmica e em tempo real proporcionada pelo Whats $A p p$ contribuído diretamente para isto.

Todas as ocupações estudantis no Rio de Janeiro também tomaram como prática, após suas consolidações, a criação de fanpages no Facebook. Um breve caminhar por estas páginas demonstra o

\footnotetext{
${ }^{4}$ Site do Linhas de Fuga http://www.linhasdefuga.com.br/ e fanpage do Facebook https://www.facebook.com/linhasdefuga/

${ }^{5}$ Documentário disponível em: https: / /www.youtube.com/watch?v $=$ Fc8ImhiVWbU\&t $=509 \mathrm{~s}$
} 
importante papel da rede social para divulgar, informar e organizar as ocupações e suas atividades, além de serem fundamentais no que tange à mobilização da sociedade para esta causa. Com mais de 15.000 curtidas, a fanpage no Facebook do Ocupa Mendes ${ }^{6}$ (Figura 2) é um bom exemplo para refletirse sobre a utilização das redes sociais pelo estudantes ocupantes. Constantemente atualizada com postagens multimídias (textos, áudios, vídeos e fotos), a página do Facebook serviu para informar e denunciar as situações de descaso com o espaço e o material escolar; divulgar as atividades realizadas no colégio, por meio de postagens que "viralizaram" na internet, ou seja, que tiveram disseminação em larga escala de conteúdo; anunciar o calendário de atividades da ocupação; além de ser um grande ambiente para o debate.

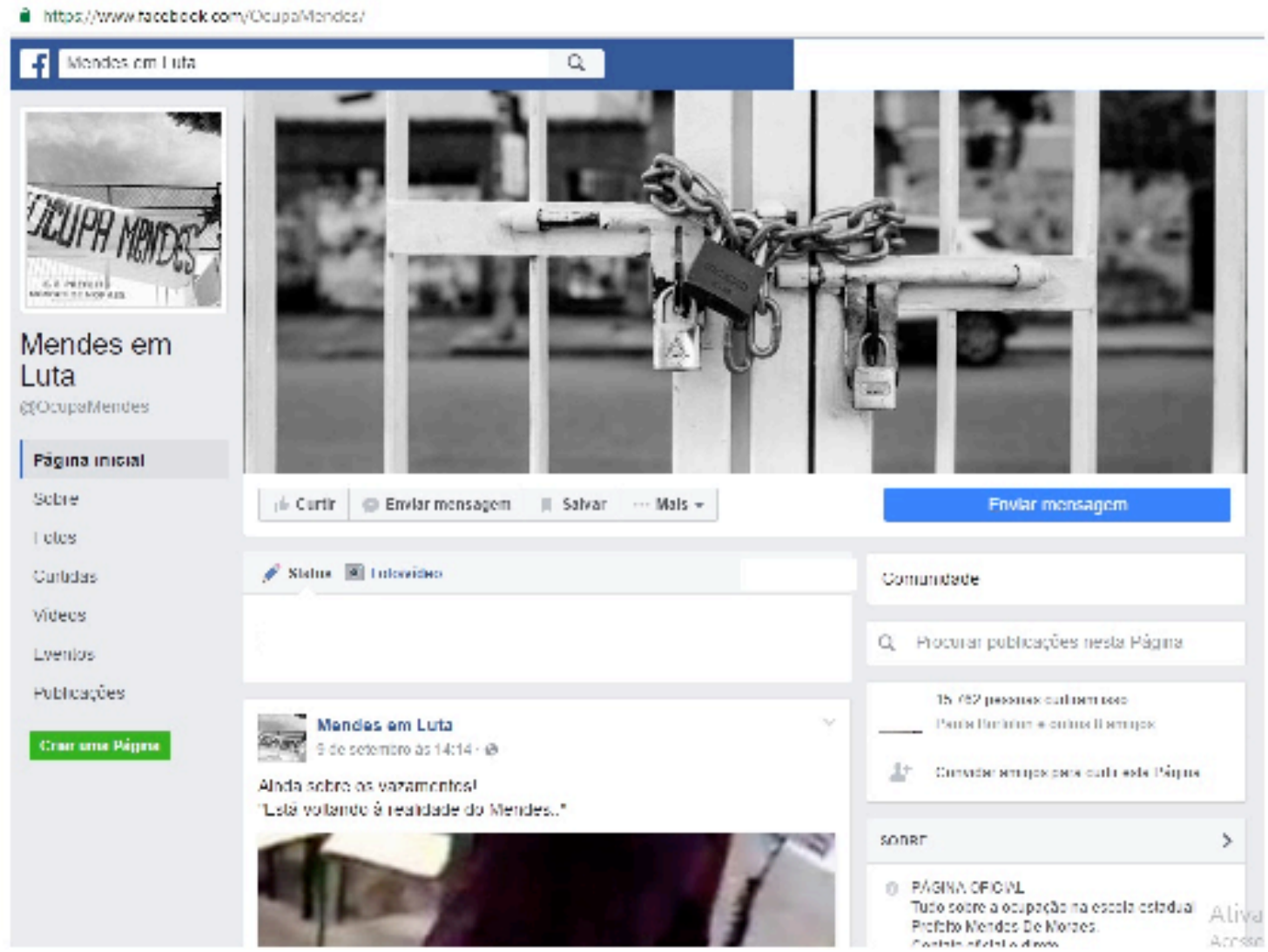

Figura 2. Fanpage do Facebook "Mendes em Luta", criada pelos alunos que ocuparam o Colégio Estadual Prefeito Mendes de Moraes (RJ). Disponível em: https://www.facebook.com/OcupaMendes/. Acesso em 13 de setembro de 2016.

Constantemente a fanpage Ocupa Mendes fornecia informes sobre o status da ocupação, pois sofreu enorme pressão do governo, da Secretaria de Estado de Educação (SEEDUC), da Polícia Militare até mesmo de milicianos para que acabasse. Graças à agilidade dos alunos e ao alcance deste canal de comunicação, uma rede de solidariedade conseguiu amenizar atos violentos e evitar que acontecimentos trágicos se dessem na escola, que muitas vezes foi atacada por um truculento

${ }^{6}$ Fanpage do Ocupa Mendes: https://www.facebook.com/OcupaMendes/ 
movimento de desocupação, organizado por estudantes contrários às ocupações de escolas e, desconfia-se, com o apoio do próprio Governo do Estado. Mesmo sob fortes ataques da mídia tradicional, a visibilidade e apoio conquistados pela ocupação obrigaram o então Secretário de Educação e outras autoridades a estar presentes muitas vezes no colégio, para conversar diretamente com os estudantes e tentar desfazer o mal-estar provocado pelas fracassadas tentativas de desocupação, que resultaram, muitas vezes, em ações violentas.

A atenção política atraiu até mesmo o Poder Judiciário, que esteve presente no Ocupa Mendes representado pelo desembargador Siro Darlan que, na ocasião, tratou de mostrar seu apoio ao movimento de luta estudantil, além de várias representações do Ministério Público. Por fim, a tensão estabelecida na região dominada por milícias e pelo tráfico de drogas levou à desocupação voluntária da escola. Mas isso só ocorreu depois da queda do Secretário de Educação do Estado, de sua assessoria e da direção do colégio, o que esboça a vitória política desta ação.

Um outro exemplo de utilização da internet para o enfrentamento de problemas pelos estudantes foi a publicização de denúncias por meio de fotos e vídeos. Uma verdadeira "caixa preta" da gestão do governo estadual do Rio de Janeiro foi aberta, revelando ao grande público o abandono e mau uso dos recursos da educação. Por meio das fanpages do Ocupa Compositor ${ }^{7}$ e Ocupa Monteiro $^{8}$, por exemplo, foram compartilhadas imagens de materiais escolares abandonados (camisas, livros, materiais esportivos e de laboratório) e de salas de aula e laboratórios que não são utilizados para as atividades escolares (Figura 3). Do mesmo modo, nas fanpages do Ocupa Compositor e Ocupa Tonhão foram compartilhados vídeos e fotos do cenário "apocalíptico" das estruturas físicas destas escolas - as imagens retratam a assustadora deterioração do patrimônio público das escolas: salas de aula, piscinas e até mesmo prédios inteiros abandonados ou destruídos. As imagens nunca haviam sido divulgadas, nem pela grande mídia. Com a viralização deste tipo de denúncias circulando largamente pela internet em perfis de militantes e coletivos de mídias alternativas, tais como o Jornal Correio do Rio, Jornal Nova Democracia, Mídia Independente Coletiva (MIC) e Coletivo Linhas de Fuga, até mesmo os canais de comunicação mais conservadores precisaram pautar em seus respectivos jornais e noticiários a questão do abandono das escolas públicas do Estado do Rio de Janeiro.

Como já apontamos o uso da internet e das redes sociais não se limitou ao caráter transmissionista unicamente para divulgação de informes e atividades. O que chama atenção é a enorme interação que tomou conta deste movimento, principalmente por meio de mensagens privadas nas páginas de Facebook e pelo Whats $A p p$. Isto possibilitou um maior contato entre as pessoas - estudantes, simpatizantes do movimento Ocupa e parceiros - para a produção de atividades diversas, como encontros, oficinas, aulas, manifestações e variados tipos de campanhas. Sobre isto, ressalta-se que a opção "criar evento" do Facebook, ajudou a viabilizar diversas passeatas e manifestações, que aconteceram em variadas regiões do Rio de Janeiro, muito além do eixo político tradicional Centro/Tijuca, e também em diversas outras cidades; acelerou a viralização de postagens, que possibilitaram o sucesso de campanhas de doações, sobretudo de alimentos e produtos de limpeza, que garantiam o dia a dia de recursos para a manutenção física das ocupações; além das campanhas, como a \#ocupatudo, que ajudaram a disseminar o fenômeno das ocupações, por todo o Estado do Rio de Janeiro e até mesmo fora dele, vide o caso de Porto Alegre, que também contou com dezenas de escolas ocupadas.

\footnotetext{
${ }^{7}$ Fanpage do Ocupa Compositor: https://www.facebook.com/ocupacompositor

${ }^{8}$ Fanpage do Ocupa Monteiro: https://www.facebook.com/ocupamonteiro/

9 Fanpage do Ocupa Tonhão: https://www.facebook.com/Ocupa-Tonh\%C3\%A3o-1595189650771284/
} 
O caso das ocupações estudantis evidencia que o uso das tecnologias interativas não traz simplesmente avanços e facilidades voltados às questões técnicas e instrumentais, como rapidez, agilidade e presteza para resolver certos problemas de comunicação, como a divulgação de informações. Para além disso, fica evidente como o uso das tecnologias interativas, neste caso a internet, traz mudanças práticas no modo de gerir, estudar, educar e ensinar que independem das normas e regras oficialmente vigentes e, por isso, expõe um outro olhar sobre estes processos, expresso por quem experiencia o problema, o que favorece a construção de um novo modo de pensar e agir, e, consequentemente, de produzir conhecimento.

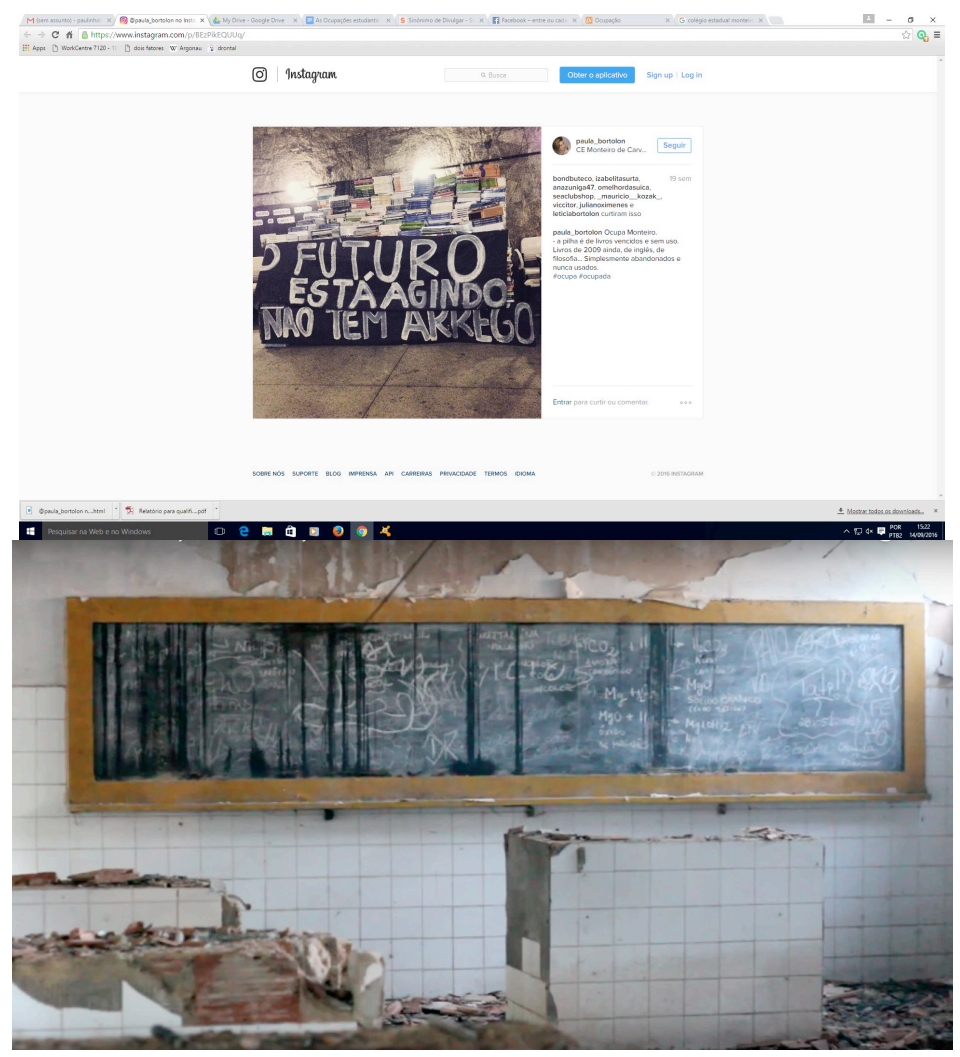

Figura 3. (A) Pilha de livros obsoletos nunca entregues aos alunos do Colégio Estadual Monteiro de Carvalho (RJ). Fonte: Acervo próprio dos autores.

(B) Estudantes da Ocupa Tonhão (Colégio Estadual Antônio Houaiss-RJ) denunciando o descaso com a educação pública no estado do Rio de Janeiro. Fonte: Coletivo de mídia independente Linhas de Fuga.

\section{As Ocupações das Escolas Estaduais do Rio de Janeiro}

Na prática, o que ocorreu dentro das ocupações é que o corpo discente organizou-se e mobilizou-se para promover palestras, minicursos, "aulões", oficinas e experiências que seriam inviáveis dentro do ensino escolar convencional (Figura 4). Dessa maneira, viabilizaram-se atividades tais como: aulas preparatórias para o Exame Nacional do Ensino Médio (ENEM); palestras de temáticas variadas, com professores da rede, acadêmicos e universitários; oficinas artísticas, como fotografia, vídeo, danças, cinema, teatro; atividades físicas como artes marciais e esportes diversos; e debates sobre temas polêmicos e atuais, como a questão racial, a sexualidade, gênero e a 
descriminalização das drogas (Figura 5). Vale dizer que as oficinas, organizadas pelos próprios estudantes sobre assuntos de interesse deles mesmos, aconteciam fora do ordenamento normal de divisão de horário, séries e da lógica de avaliação e de controle disciplinar do espaço das salas de aula. Dentre estas atividades aconteceram as seguintes oficinas: de jongo, no Colégio Estadual Prefeito Mendes de Morais; de capoeira, que ocorreram em diversas escolas; de maracatu, feita no Colégio Estadual Compositor Luiz Carlos da Vila; e a aula de Sociologia e Filosofia livre, no Colégio Estadual Antônio Houaiss.

Tudo isto foi possível pois havia uma rede de apoio e solidariedade composta por grêmios estudantis, centros acadêmicos, Diretórios Centrais de Estudantes (DCEs), departamentos e institutos universitários, sindicatos, associação de moradores, artistas, grupos culturais, coletivos de mídia livre, juristas e advogados populares.

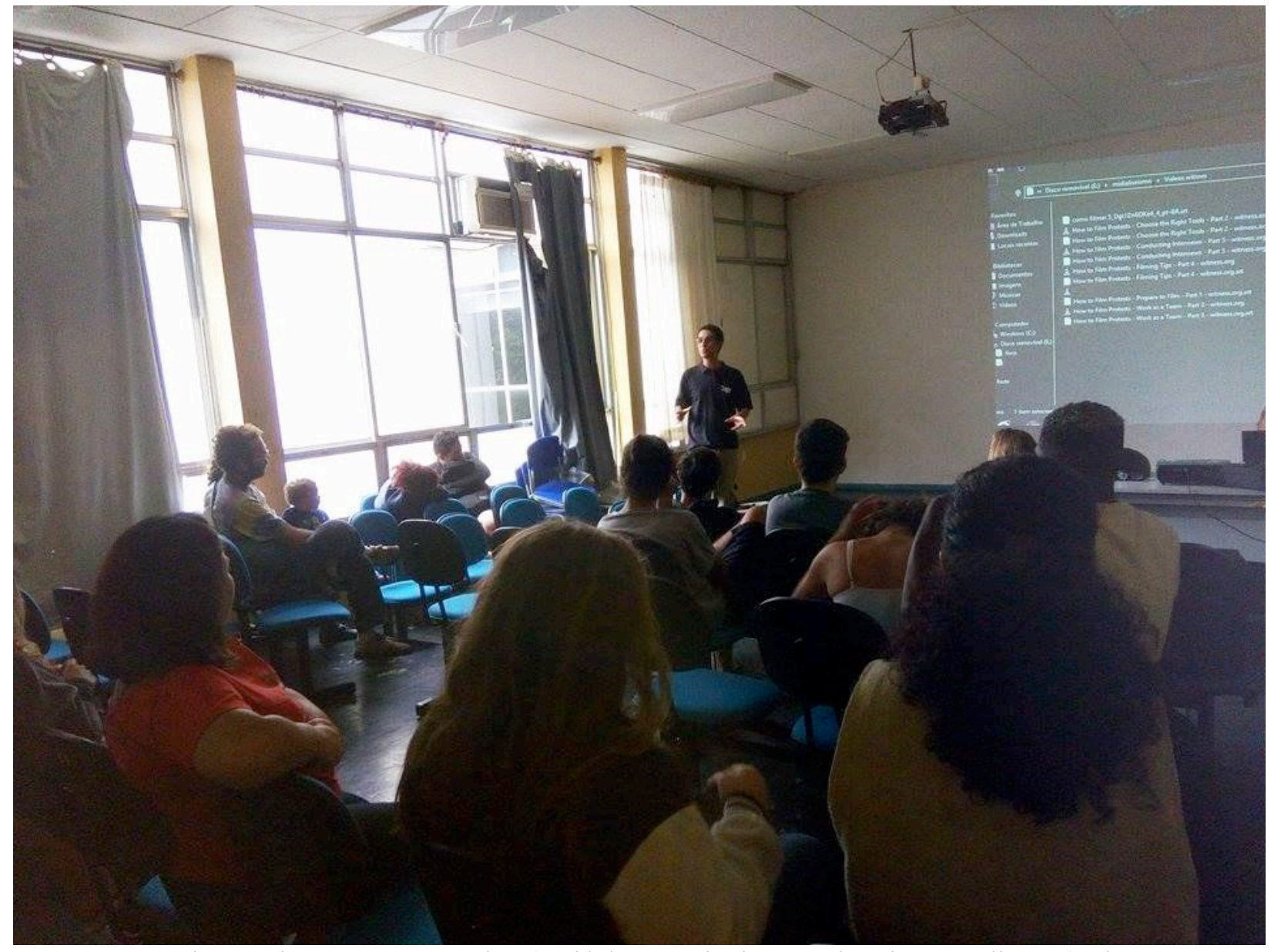

Figura 4. Estudantes do Ocupa Monteiro (Colégio Estadual Monteiro de Carvalho-RJ), durante oficina sobre comunicação e midialivrismo, em abril de 2016.

Fonte: Coletivo de mídia independente Linhas de Fuga. 


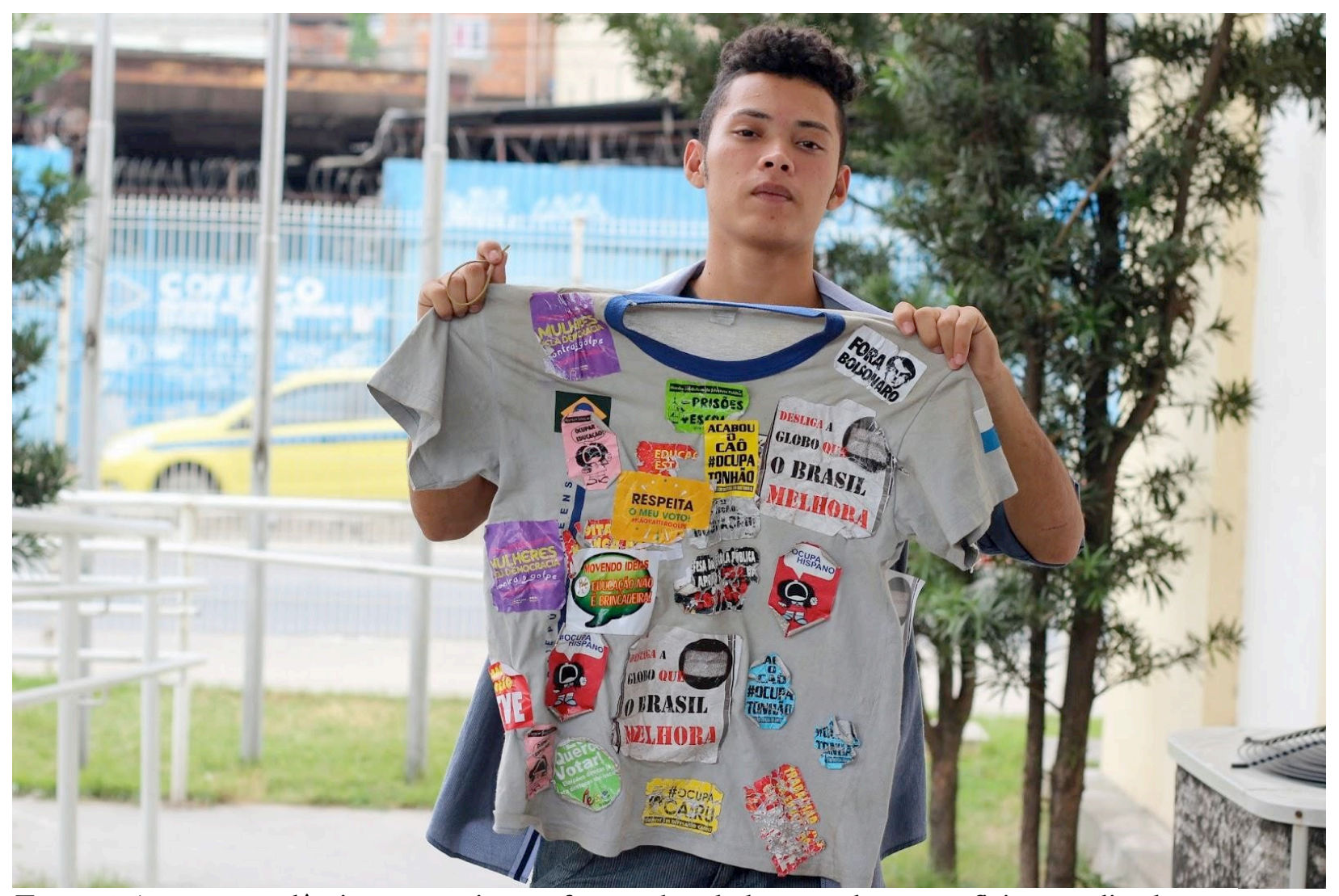

Figura 5. Assuntos polêmicos e atuais que foram abordados em algumas oficinas realizadas nas ocupações aparecem em adesivos colados na camiseta do uniforme escolar de um estudante do Colégio Estadual Compositor Luiz Carlos da Vila (RJ), em maio de 2016.

Fonte: Coletivo de mídia independente Linhas de Fuga.

De dentro das ocupações ensaiou-se a construção de uma educação que não se destina exclusivamente a promover a autonomia dos estudantes em um processo de autogestão, mas que propicia a realização prática e efetiva de outras formas de educação, ou seja, uma ação constituinte de fato. O espaço escolar foi recriado em um processo de emergência, de "baixo para cima", contrariando também o poder vertical de gestão escolar que é promovida pelo Estado. Esta prática propiciou uma aprendizagem orgânica e significativa, que de fato não separa o conhecimento da vivência, o que permitiu aos estudantes transcender a esterilidade da escola tradicional. $\mathrm{O}$ movimento das ocupações, também evidenciou os problemas que envolvem a educação pública no Brasil por meio do contato prático dos estudantes com a estrutura de funcionamento de suas escolas, trazendo à tona diversos absurdos, relativos à estrutura física do colégio e dos materiais de apoio para o ensino, conforme já mencionado anteriormente, que os fizeram refletir o que é o colégio, como ele está e como poderia ser. É o que mostra o depoimento feito por um estudante secundarista carioca para um jornal local ${ }^{15}$ :

Vinha para zoar. Agora, entendi o propósito disso. O livro de que eu precisava e não recebi está mofando aqui. A escola está cheia de ratos. Tudo isso me levou a ocupar a escola, e a ocupação me mudou. Eu vinha à escola pra zoar. Agora entendi o propósito disso aqui. Parei para pensar: o que estou fazendo? Tenho de mudar (Alfano, 2016). 
Por esta perspectiva, as ocupações estudantis mostram-se como um ato de resistência frente ao poder constituído, como bem colocou Gallo (2003) ao apresentar os conceitos de educação maior e educação menor ao apropriar-se do debate de Deleuze apud Chomsky (2012) sobre a Literatura Maior e Menor e deslocá-lo para o campo da educação.

A educação maior é aquela dos planos decenais e das políticas públicas de educação, dos parâmetros e das diretrizes, aquela da constituição e da lei de Diretrizes e Base da Educação Nacional, pensada e produzida pelas cabeças bem-pensantes a serviço do poder. A educação maior é aquela instituída e que quer instruir-se, fazer-se presente, fazer-se acontecer. (...) é aquela dos grandes mapas e projetos. A educação menor é um ato de revolta e de resistência. Revolta contra os fluxos instituídos, resistência às políticas impostas; sala de aula como trincheira, como toca do rato, o buraco do cão. Sala de aula como espaço a partir do qual traçamos nossas estratégias, estabelecemos nossa militância, produzindo um presente e um futuro aquém ou para além de qualquer política educacional. Uma educação menor é um ato de singularização e de militância (Gallo, 2003, p. 64).

A educação menor feita pelos estudantes é uma contraposição ao controle institucional, que se concretizou nas ocupações dos colégios. Ao invés de limitar-se à formulação de políticas que regulariam os atos cotidianos do processo educativo, as ocupações secundaristas agiram sobretudo por meio do enfrentamento dos problemas que se colocavam em meio ao cotidiano do movimento, quer fossem relacionados à reparação de danos estruturais dos colégios, como iluminação ou limpeza, ou voltados para questões táticas como, por exemplo, segurança e alimentação. O caso estudantil, assim, tornou-se também um exemplo de comunidade cooperativa, que segundo Chomsky (2012) é uma estrutura social construída por quem vivencia o problema e age livremente trabalhando para si, abrindo condições para o reconhecimento de sua causa na sociedade, o que permite que a experiência - as ações desenvolvidas - e os resultados alcançados espalhem-se mais amplamente para toda a comunidade.

Este movimento estudantil, que no dia a dia reinventava o espaço escolar e ganhava reconhecimento na sociedade, pegou de surpresa as autoridades do governo e até mesmo a militância política tradicional, que ainda encontra muita dificuldade para entender o que houve de fato nas ocupações secundaristas. Sua potência encontra-se tanto no seu caráter distribuído, interativo e dinâmico, típico de sistemas abertos, como a internet, no qual todos os envolvidos são atores ativos no processo e não há necessidade de um líder central ou mediadores, embora pudesse haver representantes responsáveis por conduzir ações específicas; quanto na crítica à representatividade burocrática e aos movimentos políticos tradicionais, que despontaram em todo um conjunto de práticas diferenciadas que vieram à tona no país a partir de 2013, com as jornadas de junho.

A discordância do poder constituído e do atual modelo de democracia representativa capitalista já havia levado manifestantes de diversos países a ocupar espaços públicos na crítica ao autoritarismo e às desigualdades promovidas pelo poder econômico do mercado, responsável pela concentração de riquezas, poder e participação política a uma parte ínfima da população do mundo. Em 2011, movimentos de ocupação tomaram cidades do mundo todo: o 15M em Madri; o Occupy Wall Street em Nova Iorque; os manifestantes da Praça Tahrir no Cairo... Esta mesma lógica, marcada pela insatisfação social no tocante às desigualdades também fundamentou o movimento de ocupação secundarista no Brasil (Figura 6). Para entender todo esse processo, no entanto, é preciso ter em mente que as ocupações são movimentos de reação popular que emergem não apenas para tentar entender o mundo, mas para mudá-lo. Por meio da aprendizagem e da participação, sendo a 
construção de vínculos um aspecto estruturante destes movimentos, as ocupações podem trazer uma mudança de consciência que se reflete taticamente, como no exemplo apresentado dos estudantes, e que talvez mostrem um caminho mais humano para nossa sociedade.

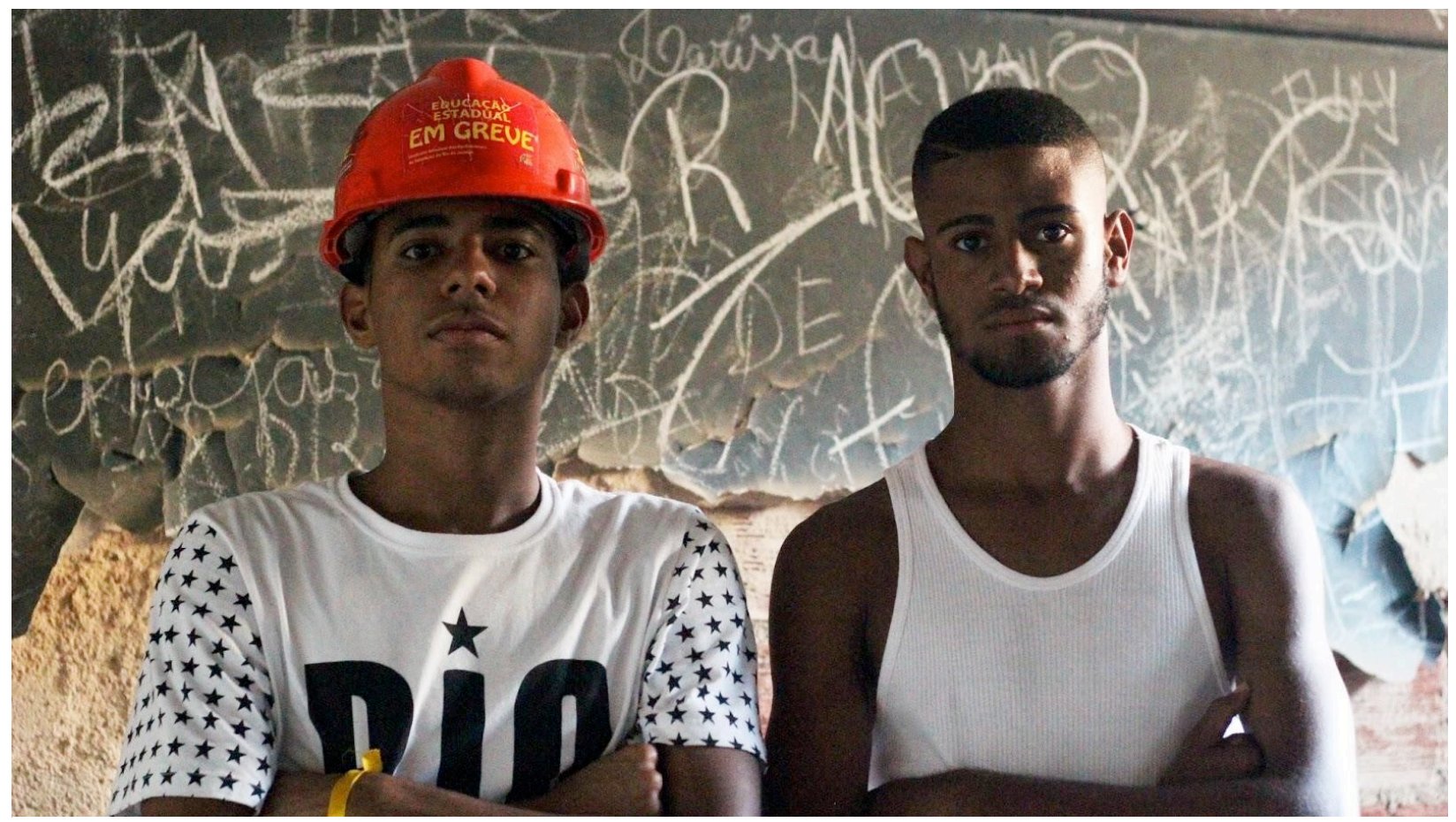

Figura 6. Estudantes do Colégio Estadual Antônio Houaiss (RJ), durante o movimento de ocupação “Ocupa Tonhão". Ao fundo o quadro negro deteriorado e sem manutenção. Maio de 2016. Fonte: Coletivo de mídia independente Linhas de Fuga.

\section{Considerações Finais}

A iniciativa estudantil de luta pela educação é um exemplo de como as mobilizações para superação de problemas podem ocorrer independentemente dos poderes constituídos e das normas vigentes. Nestes movimentos a interação entre as pessoas torna-se tão intensa que a expressão pessoal dá lugar ao coletivo, em um processo de sincronização marcado por um tanto de espontaneidade. No caso das ocupações dos colégios os estudantes secundaristas mostraram, na prática, como romper com o paradigma de verticalização da política tradicional e com a lógica de funcionamento dos colégios.

Por meio da internet pela liberdade de acesso às informações que ela possibilita, justamente por ser um espaço de não-controle, os estudantes secundaristas protagonizaram um movimento que trouxe junto a novidade de mostrar para a sociedade uma questão outrora restrita a eles e àqueles envolvidos mais diretamente com os colégios. Desse modo, os estudantes puderam disseminar para a sociedade uma série de informações, divulgadas pelas redes sociais e por aplicativos de mensageria instantânea da internet, que viralizaram pela rede expondo tanto a situação precária da educação pública no Brasil como as ações realizadas por eles no tocante à melhoria das condições físicas dos colégios e às atividades educativas e culturais que aconteciam durante as ocupações. Entre curtidas, compartilhamentos e discussões que tomaram a rede, os estudantes foram ganhando adeptos para a sua causa, os quais se solidarizaram e contribuíram das mais diversas formas com as ocupações. 
Além disso, os alunos mostraram uma contemporaneidade com este movimento de ocupações que, por si, só revela uma nova forma de se pensar ações políticas, muito alinhadas às transformações do mundo atual em que novos coletivos surgem e, facilitados pela interação que a internet proporciona, conseguem mais amplamente revelar suas questões para a sociedade.

Nisto repousa a necessidade de refletir sobre a relação orgânica entre o atual levante estudantil secundarista e a internet, para entender este movimento para além das interpretações políticas mais tradicionais. Por um lado, é preciso compreender o movimento de ocupação dos colégios de uma outra forma que não deslize em explicações político-partidárias, o que traz grandes dificuldades para a compreensão dos novos movimentos sociais para além de uma ortodoxia militante. Por outro lado, é fundamental entender a internet não apenas do ponto de vista da tecnologia facilitadora de processos comunicativos ou informacionais, mas também como um meio que dá vida aos processos de mudanças sociais e políticas mediante uma lógica de resistência e subversão, bem como este caso dos estudantes secundaristas mostra.

Os estudantes secundaristas que ocuparam seus colégios e romperam com a lógica do sistema de ensino do Brasil, mostraram a importância das ações de base e ratificaram os dizeres de Deleuze sobre a importância de resistir e criar:

Acreditar no mundo é o que mais nos falta; nós perdemos completamente o mundo, nos desapossaram dele. Acreditar no mundo significa principalmente suscitar acontecimentos, mesmo pequenos, que escapem ao controle, ou engendrar novos espaços-tempos, mesmo de superfície ou volume reduzidos (...). É ao nível de cada tentativa que se avaliam a capacidade de resistência ou, ao contrário, a submissão a um controle (Deleuze, 1992, p. 218).

\section{Referências}

Alfano, B. (2016). A rotina dos alunos que 'moram' em um colégio ocupado de Bangu. Acesso em: 2 de maio de 2016. Disponível em: de https:/ / extra.globo.com/noticias/educacao/a-rotinados-alunos-que-moram-em-um-colegio-ocupado-de-bangu-19201808.html

Althusser, L. (1998). Aparelhos Ideológicos do Estado: Nota sobre aparelhos ideológicos do Estado. ( $\left.7^{\circ} \mathrm{ed}\right)$. Rio de Janeiro: Graal.

Aranha, M. L. de A. (2006). Filosofia da Educação (3e ed). São Paulo: Moderna.

Bourdieu, P., \& Passeron, J.-C. (1975). A Reproducão: Elementos para uma Teoria do Sistema de Ensino. Rio de Janeiro: Francisco Alves.

Brasil. (1996). Lei Federal n ${ }^{\circ}$ 9.394/96, de 20 de dezembro de 1996. Estabelece as diretrizes e bases da educação nacional. Diário Oficial da União, Ano CXXXIV, n. 248, 23 de dezembro de 1996, 27833-27841. Brasília.. Disponível em: <http://www.planalto. gov.br/ccivil_03/leis/L9394.htm>. Acesso em: 27 jan. 2017.

Chomsky, N. (2012). Occupy: Reflections on Class War, Rebellion and Solidarity. (2 ed). Brooklyn: Zuccotti Park Press.

Deleuze, G. (1992). Conversações. (P. Pál Pelbart, Trad.). São Paulo.

Dussel, E. (1995). Filosofia da Libertação: Crítica à ideologia da exclusão. (G. I. Massiat, Trad.). São Paulo: Paulus.

Faure, S. (2015). Colmeia: Uma experiência pedagógica (1ºd). Biblioteca Terra Livre.

Ferrer Guardia, F. (1905). La escuela moderna. Barcelona. Disponível em: http:/ / metalmadrid.cnt.es/cultura/libros/francisco-ferrer-guardia-la-escuela-moderna.pdf

Freire, P. (1980). Educação como prática da liberdade. Paz e Terra. 
Freire, P. (2005). Pedagogia do Oprimido (42 ed). Rio de Janeiro: Paz e Terra.

Frigotto, G., Motta, V. da, Gama, Z., \& Algebaile, E. (2011). Plano de Metas da Educação do Rio de Janeiro: do economicismo ao cinismo. Plano de Metas da Educação do Rio de Janeiro. Disponível em: http://www.uff.br/observatoriojovem/materia/plano-de-metas-daeduca $\sim \mathrm{A} / \mathrm{T} 1 /$ textsection $\% 20 \sim \mathrm{A} / \mathrm{T} 1 /$ textsterling\%20o-do-rio-de-janeiro-doeconomicismo-ao-cinismo

Gallo, S. (2003). Deleuze e a Educação. Belo Horizonte: Autêntica.

Gentili, P. A. A. (1998). Falsificação do Consenso Simulacro e Imposição na Reforma Educacional do Neoliberalismo. Petrópolis: Vozes.

Gentili, P. A. A. (Org.). (2001). Pedagogia da exclusão: Crítica ao neoliberalismo em educação (9º $\mathrm{ed}$ ). Petrópolis: Vozes.

Gentili, P. A. A., \& da Silva, T. T. (Orgs.). (2002). Neoliberalismo, qualidade total e educação: Visões críticas. $\left(11^{\circ}\right.$ ed). Petrópolis: Vozes.

Guattari, F. (1980). Revolução molecular: Pulsações políticas do desejo. São Paulo: Editora Brasiliense.

Guattari, F., \& Rolnik, S. (2005). Micropolítica: cartografias do desejo ( $9^{\circ}$ ed). Petrópolis: Vozes.

Hardt, M., \& Negri, A. (2005). Multidão. Guerra e Democracia na Era do Império. (Clóvis Marques, Trad.). Rio de Janeiro: Record.

Johnson, S. (2003). Emergência. A dinâmica de rede em formigas, cérebros, cidades e softwares. Zahar.

Manifesto dos Pioneiros da Educação Nova. (1932). A Reconstrução Educacional do Brasil. Ao Povo e ao Governo. São Paulo.

Santos, A. dos, Martins, B. C., \& Santos, N. B. dos. (2014). Novas mídias como arquitetura pedagógica: A experiência do NEXT/Fiocruz. In Comunicação e Cultura na Era de Tecnologias Midiáticas Onipresentes e Oniscientes. São Paulo: ESPM.

Santos, M. do S. dos, \& Mesquita, P. (2007). As matilhas de Hobbes: O modelo da pedagogia por competência. São Paulo: Edumesp.

Santos, N. B. dos. (2005). Notas sobre a Educação a Distância e a Revolução Tecnológica. Revista TEXTOS de la CiberSociedad, 6, 1-14.

Santos, N. B. dos. (2006). A educação a distância, a internet e a educação formal. Liinc em Revista, 2(1), 53-70.

Santos, N. B. dos, Santos, A. dos, Melca, F., Bortolon, P. C., \& Rocha, R. de C. M. da. (2014). Ambientes de Nuvem para Pesquisa e Educação: O caso do NEXT - Fiocruz. In XV Enancib - Além das nuvens: expandindo as fronteiras da Ciência da Informação, 1, 2395-2414. Belo Horizonte: Enancib.

Serres, M. (2000). Novas Tecnologias e sociedade pedagógica. Uma conversa com Michel Serres. Interface - Comunicação, Saúde, Educação, 4(6), 129-142.

Strogatz, S. (2004). The science of sync. Disponível em: www.ted.com/talks/ steven_strogatz_on_sync?language=en. Acesso em: 16 de março de 2016.

Teixeira, A. (1953). A crise educacional brasileira. Revista Brasileira de Estudos Pedagógicos, 19(50), $20-$ 43.

Teixeira, A. (1967a). A Escola Parque da Bahia. Revista Brasileira de Estudos Pedagógicos, 47(106) 246253.

Teixeira, A. (1967b). Centro Educacional Carneiro Ribeiro. Revista Brasileira de Estudos Pedagógicos, 31(73), 246-253. 


\section{Sobre o Autores}

\section{Diego Felipe de Souza Queiroz SEEDUC/RJ enxame22@gmail.com}

Mestrando em Filosofia e Ensino (PPFEN/Cefet/RJ). Graduado em Filosofia pela Universidade do Estado do Rio de Janeiro (2010). Atualmente é docente da Escola Estadual Adlai Stevenson e e do Instituto de Estadual Carmela Dutra. Leccionando as disciplinas filosofia, sociologia e história da filosofia e educação. Também compõe o grupo de pesquisa "Tecnologias, Culturas e Práticas Interativas e Inovação em Saúde" da Fundação Oswaldo Cruz, e atua como midialivrista e documentarista sendo responsável pelos documentários "Cinturão de Giz", "Luto pela Educação",'Vândalos e Baderneiros" e também por grande parte dos vídeos do coletivo Linhas de Fuga.

Lattes: http:/ /lattes.cnpq.br/0103443747550623

\section{Paula Chagas Bortolon PPGICS/Icict/Fiocruz} paulinhabortolon@gmail.com

Doutoranda em Informação e Comunicação em Saúde no PPGICS/Icict/Fiocruz. Mestre em em Saúde Pública pela Ensp/Fiocruz. Pesquisadora do Grupo de Pesquisa/CNPq/Fiocruz "Tecnologias, Culturas e Práticas Interativas e Inovação em Saúde" e do Núcleo de Experimentação de Tecnologias Interativas (Next/Ensp/Fiocruz). Sensível ao multiculturalismo, percebe nas dinâmicas participativas e interativas um grande meio para compartilhar experiências na busca pela resolução de problemas e nas tecnologias interativas um potencial espaço de participação para coletivos outrora silenciados. Professora convidada do Curso de Especialização em Informação Científica e Tecnológica em Saúde, do Icict/Fiocruz.

Lattes: http://lattes.cnpq.br/8680693540908255

\section{Rita de Cássia Machado da Rocha \\ PGEBS/IOC/Fiocruz \\ ritamachado86@gmail.com}

Doutoranda em Ensino Biociências e Saúde. Mestre em Ensino Biociências e Saúde (PGEBS/IOC/FIOCRUZ). Possui graduação em Comunicação Social com habilitação em Jornalismo. Atua com Educação em Rede e Educação em Saúde, Tecnologias Interativas, Mídias Digitais, Jornalismo Científico e Transmissões on air. Colaboradora do Grupo de Pesquisa/CNPq/Fiocruz "Tecnologias, Culturas e Práticas Interativas e Inovação em Saúde" e do Núcleo de Experimentação de Tecnologias Interativas (Next/Ensp/Fiocruz) e do Laboratório de Inovações em Terapias, Ensino e Bioprodutos do Instituto Oswaldo Cruz (LITEB/IOC/Fiocruz). Lattes: http://lattes.cnpq.br/1681014750804265 


\title{
arquivos analíticos de políticas educativas
}

Volume 25 Número 104
9 de outubro 2017
ISSN 1068-2341

\begin{abstract}
@)
SORERIGHIS RESERED O Copyright e retido pelo/a o autor/a (ou primeiro co-autor) que outorga o direito da primeira publicação à revista Arquivos Analíticos de Políticas Educativas. Más informação da licença de Creative Commons encontram-se em http://creativecommons.org/licenses/by-nc-nd/2.5. Qualquer outro uso deve ser aprovado em conjunto pelo/s autor/es e por AAPE/EPAA. AAPE/EPAA é publicada por Mary Lou Fulton Institute Teachers College da Arizona State University. Os textos publicados em AAPE são indexados por CIRC (Clasificación Integrada de Revistas Científicas, Espanha) DIALNET (Espanha),Directory of Open Access Journals, Education Full Text (H.W. Wilson), EBSCO Education Research Complete, ERIC, QUALIS A1 (Brasil), SCImago Journal Rank; SCOPUS, SOCOLAR (China).
\end{abstract}

Curta a nossa comunidade EPAA's Facebook https://www.facebook.com/EPAAAAPE e Twitterfeed@epaa_aape. 


\title{
arquivos analíticos de políticas educativas conselho editorial
}

\begin{abstract}
Editor Executivo: Gustavo E. Fischman (Arizona State University)
Editoras Associadas: Geovana Mendonça Lunardi Mendes (Universidade do Estado de Santa Catarina), Marcia Pletsch, Sandra Regina Sales (Universidade Federal Rural do Rio de Janeiro)
\end{abstract}

\author{
Almerindo Afonso \\ Universidade do Minho \\ Portugal
}

Rosanna Maria Barros Sá

Universidade do Algarve

Portugal

\section{Maria Helena Bonilla}

Universidade Federal da Bahia

Brasil

Rosa Maria Bueno Fischer

Universidade Federal do Rio Grande do Sul, Brasil

\section{Alice Casimiro Lopes}

Universidade do Estado do Rio de

Janeiro, Brasil

Suzana Feldens Schwertner

Centro Universitário Univates

Brasil

Flávia Miller Naethe Motta

Universidade Federal Rural do Rio de

Janeiro, Brasil

\section{Alexandre Fernandez Vaz \\ Universidade Federal de Santa \\ Catarina, Brasil}

\section{Regina Célia Linhares Hostins \\ Universidade do Vale do Itajaí, Brasil}

Alfredo Macedo Gomes
Universidade Federal de Pernambuco
Brasil

Jefferson Mainardes

Universidade Estadual de Ponta

Grossa, Brasil

Jader Janer Moreira Lopes

Universidade Federal Fluminense e

Universidade Federal de Juiz de Fora, Brasil

\section{Debora Nunes}

Universidade Federal do Rio Grande do Norte, Brasil

\section{Alda Junqueira Marin}

Pontifícia Universidade Católica de São Paulo, Brasil

\section{Dalila Andrade Oliveira}

Universidade Federal de Minas

Gerais, Brasil
José Augusto Pacheco

Universidade do Minho, Portugal

Jane Paiva

Universidade do Estado do Rio de

Janeiro, Brasil

\section{Paulo Alberto Santos Vieira}

Universidade do Estado de Mato

Grosso, Brasil

Fabiany de Cássia Tavares Silva

Universidade Federal do Mato

Grosso do Sul, Brasil

\section{António Teodoro}

Universidade Lusófona

Portugal

\section{Lílian do Valle}

Universidade do Estado do Rio de Janeiro, Brasil

\section{Alfredo Veiga-Neto}

Universidade Federal do Rio Grande do Sul, Brasil 


\section{archivos analíticos de políticas educativas consejo editorial}

Editor Consultor: Gustavo E. Fischman (Arizona State University)

Editores Asociados: Armando Alcántara Santuario (Universidad Nacional Autónoma de México), Jason Beech (Universidad de San Andrés), Ezequiel Gomez Caride (Pontificia Universidad Católica Argentina), Antonio Luzon (Universidad de Granada), José Luis Ramírez Romero (Universidad Autónoma de Sonora, México)

Claudio Almonacid

Universidad Metropolitana de

Ciencias de la Educación, Chile

Miguel Ángel Arias Ortega

Universidad Autónoma de la

Ciudad de México

Xavier Besalú Costa

Universitat de Girona, España

Xavier Bonal Sarro Universidad

Autónoma de Barcelona, España

Antonio Bolívar Boitia

Universidad de Granada, España

José Joaquín Brunner Universidad

Diego Portales, Chile

Damián Canales Sánchez

Instituto Nacional para la

Evaluación de la Educación,

México

Gabriela de la Cruz Flores

Universidad Nacional Autónoma de

México

Marco Antonio Delgado Fuentes

Universidad Iberoamericana,

México

Inés Dussel, DIE-CINVESTAV, México

Pedro Flores Crespo Universidad

Iberoamericana, México
Ana María García de Fanelli

Centro de Estudios de Estado y

Sociedad (CEDES) CONICET,

Argentina

Juan Carlos González Faraco

Universidad de Huelva, España

María Clemente Linuesa

Universidad de Salamanca, España

Jaume Martínez Bonafé

Universitat de València, España

Alejandro Márquez Jiménez

Instituto de Investigaciones sobre la Universidad y la Educación,

UNAM, México

María Guadalupe Olivier Tellez,

Universidad Pedagógica Nacional,

México

Miguel Pereyra Universidad de

Granada, España

Mónica Pini Universidad Nacional

de San Martín, Argentina

Omar Orlando Pulido Chaves

Instituto para la Investigación

Educativa y el Desarrollo

Pedagógico (IDEP)

Paula Razquin Universidad de San

Andrés, Argentina

José Ignacio Rivas Flores

Universidad de Málaga, España
Miriam Rodríguez Vargas

Universidad Autónoma de

Tamaulipas, México

José Gregorio Rodríguez

Universidad Nacional de Colombia, Colombia

Mario Rueda Beltrán Instituto de Investigaciones sobre la Universidad y la Educación, UNAM, México

José Luis San Fabián Maroto

Universidad de Oviedo, España

Jurjo Torres Santomé, Universidad de la Coruña, España

Yengny Marisol Silva Laya

Universidad Iberoamericana,

México

Ernesto Treviño Ronzón

Universidad Veracruzana, México

Ernesto Treviño Villarreal

Universidad Diego Portales

Santiago, Chile

Antoni Verger Planells

Universidad Autónoma de

Barcelona, España

Catalina Wainerman

Universidad de San Andrés, Argentina

Juan Carlos Yáñez Velazco

Universidad de Colima, México 


\section{education policy analysis archives editorial board}

Lead Editor: Audrey Amrein-Beardsley (Arizona State University)

Editor Consultor: Gustavo E. Fischman (Arizona State University)

Associate Editors: David Carlson, Lauren Harris, Margarita Jimenez-Silva, Eugene Judson, Mirka Koro-

Ljungberg, Scott Marley, Jeanne M. Powers, Iveta Silova, Maria Teresa Tatto (Arizona State University)

Cristina Alfaro San Diego State

University

Gary Anderson New York

University

Michael W. Apple University of

Wisconsin, Madison

Jeff Bale OISE, University of

Toronto, Canada

Aaron Bevanot SUNY Albany

David C. Berliner Arizona

State University

Henry Braun Boston College

Casey Cobb University of

Connecticut

Arnold Danzig San Jose State

University

Linda Darling-Hammond

Stanford University

Elizabeth H. DeBray University of Georgia

Chad d'Entremont Rennie Center for Education Research \& Policy

John Diamond University of

Wisconsin, Madison

Matthew Di Carlo Albert Shanker Institute

Michael J. Dumas University of California, Berkeley

Kathy Escamilla University of Colorado, Boulder

Melissa Lynn Freeman Adams

State College

Rachael Gabriel

University of Connecticut

Amy Garrett Dikkers University of North Carolina, Wilmington

Gene V Glass Arizona

State University
Ronald Glass University of California, Santa Cruz

Jacob P. K. Gross University of Louisville

Eric M. Haas WestEd

Julian Vasquez Heilig California State University, Sacramento

Kimberly Kappler Hewitt University of North Carolina Greensboro

Aimee Howley Ohio University

Steve Klees University of Maryland

Jaekyung Lee

SUNY Buffalo

Jessica Nina Lester

Indiana University

Amanda E. Lewis University of Illinois, Chicago

Chad R. Lochmiller Indiana

University

Christopher Lubienski Indiana University

Sarah Lubienski Indiana University

William J. Mathis University of

Colorado, Boulder

Michele S. Moses University of Colorado, Boulder

Julianne Moss Deakin

University, Australia

Sharon Nichols University of Texas, San Antonio

Eric Parsons University of

Missouri-Columbia

Susan L. Robertson Bristol

University, UK

Gloria M. Rodriguez

University of California, Davis
R. Anthony Rolle University of Houston

A. G. Rud Washington State University

Patricia Sánchez University of University of Texas, San Antonio Janelle Scott University of California, Berkeley Jack Schneider College of the Holy Cross

Noah Sobe Loyola University

Nelly P. Stromquist University of Maryland

Benjamin Superfine University of Illinois, Chicago

Sherman Dorn

Arizona State University

Adai Tefera Virginia

Commonwealth University

Tina Trujillo University of California, Berkeley

Federico R. Waitoller University of Illinois, Chicago

Larisa Warhol

University of Connecticut

John Weathers University of Colorado, Colorado Springs

Kevin Welner University of Colorado, Boulder

Terrence G. Wiley Center for Applied Linguistics

John Willinsky

Stanford University

Jennifer R. Wolgemuth University of South Florida

Kyo Yamashiro Claremont Graduate University 